\title{
Clinical Effects and Safety of Different Transarterial Chemoembolization Methods for Bridging and Palliative Treatments in Hepatocellular Carcinoma
}

\section{Isabelle Mohr}

University Hospital Heidelberg Medical Clinic: Universitatsklinikum Heidelberg Medizinische Klinik

\section{Marie Vogeler}

University Hospital Heidelberg Medical Clinic: Universitatsklinikum Heidelberg Medizinische Klinik

\section{Jan Pfeiffenberger}

University Hospital Heidelberg Medical Clinic: Universitatsklinikum Heidelberg Medizinische Klinik

\section{Simon David Sprengel}

University Hospital Heidelberg: Departement of Radiologie

\section{Miriam Klauss}

Heidelberg University Hospital, Department of Radiologie

\section{Boris Radeleff}

Sana Klinikum Hof GmbH

\section{Andreas Teufel}

University Hospital Mannheim of University of Heidelberg Faculty of Medicine Mannheim:

Universitatsklinikum Mannheim

\section{De-Hua Chang}

Heidelberg University Hospital, Departement of Radiology

\section{Christoph Springfeld}

Heidelberg University Hospital; Department of Medical Oncology, National Center for Tumor Diseases

Thomas Longerich

Heidelberg University Hospital, Departement of Pathology

\section{Uta Merle}

University Hospital Heidelberg Medical Clinic: Universitatsklinikum Heidelberg Medizinische Klinik

\section{Arianeb Mehrabi}

University Hospital Heidelberg Department of General, Visceral and Transplantation Surgery

\section{Karl Heinz Weiss}

Salem Hospital Heidelberg, Internal Medicinme

\section{Markus Mieth ( $\nabla$ markus.mieth@med.uni-heidelberg.de )}

Heidelberg, University Hospital: Department of General, Viszeral and Transplantation Surgery https://orcid.org/0000-0002-6331-9436 


\section{Research Article}

Keywords: TACE, chemoembolization, liver cancer, HCC, liver transplant

Posted Date: May 17th, 2021

DOl: https://doi.org/10.21203/rs.3.rs-511175/v1

License: (c) (i) This work is licensed under a Creative Commons Attribution 4.0 International License. Read Full License

Version of Record: A version of this preprint was published at Journal of Cancer Research and Clinical Oncology on January 25th, 2022. See the published version at https://doi.org/10.1007/s00432-02103900-3. 


\section{Abstract}

\section{Purpose:}

We assessed and compared clinical effects and safety endpoints of three methods of transarterial chemoembolization (TACE), conventional (CTACE), with drug-eluting beads (DEB-TACE), and with degradable starch microspheres (DSM-TACE), used in patients with hepatocellular carcinoma (HCC) in the bridging to liver transplant (LT) and the palliative setting.

\section{Methods:}

In our center, 148 patients with HCC underwent 492 completed TACE procedures between 2008 and 2017 (158 for bridging to LT; 334 for palliative treatment) which we analyzed retrospectively. Of these procedures, 348 were DEB-TACE, 60 cTACE, and 84 DSM-TACE.

\section{Results:}

The cTACE procedure revealed a significantly longer period of hospitalization $(p=0.02)$, increased occurrence of nausea $(p=0.025)$, and rise in alanine transaminase (ALT) levels $(p=0.001)$, especially in the palliative setting. In the bridging to LT cohort, these clinical endpoints did not reach statistical significance.

\section{Conclusions:}

The clinical safety of different TACE methods for HCC in both the palliative and the bridging to LT setting was equivalent. In the palliative setting, the CTACE procedure revealed an increased risk for adverse clinical effects such as nausea, elevation of ALT, and a prolonged period of hospitalization what might either be related to the systemic effects of the chemotherapeutic agent or to the differences in both collectives. Thus, further studies must be conducted on a larger number of TACE procedures to effectively explore the clinical side effects of the various TACE variants.

\section{Introduction}

Management and prognosis of hepatocellular carcinoma (HCC) patients depends on tumor status, general health, and recent liver functional reserve (Okuda, Ohtsuki et al. 1985, Llovet, Bustamante et al. 1999, Marrero, Fontana et al. 2005, Cabibbo, Enea et al. 2010). Curative treatments, such as resection, liver transplantation, or local ablation, are generally restricted to limited tumor mass (Bruix and Sherman 2005, Llovet, Schwartz et al. 2005). Transarterial chemoembolization (TACE) is currently considered the first line-therapy for intermediate-stage HCC patients (Llovet and Bruix 2003, Llovet, Di Bisceglie et al. 2008, Bruix and Sherman 2011), aiming for local tumor control (Arii, Yamaoka et al. 2000, lkai, Arii et al. 2004, Takayasu, Arii et al. 2006, Lee, Huo et al. 2012). Apart from its use in the palliative setting for intermediate and advanced tumor stages, TACE is applied as bridging treatment to liver transplantation (LT) in order to control local tumor growth and maintain the patient's tumor load (Majno, Adam et al. 
1997, Decaens, Roudot-Thoraval et al. 2005, Porrett, Peterman et al. 2006, Bruix and Sherman 2011, Kollmann, Selzner et al. 2017). The aim of TACE is to induce tumor necrosis of medium local application of high-dose chemotherapy and additional hypoxia (through vascular occlusion) (Zangos, Eichler et al. 2007).

The efficacy of general TACE procedures has already been evaluated several times in patients with purely palliative therapy indications (Biselli et al. 2005; Llovet and Bruix 2003; Takayasu et al. 2006). However, the benefits of TACE as bridging therapy for liver transplantation have been studied to a much lesser extent, with unambiguous results (Decaens et al. 2005; Fujiki et al. 2011; Holowko et al. 2015; Majno et al. 1997; Porrett et al. 2006). Currently, different variants of TACE are in use. These include conventional TACE (CTACE), drug-eluting bead TACE (DEB-TACE), and TACE with degradable starch microspheres (DSM-TACE). In CTACE, a mixture of the chemotherapeutic agent and an embolizing material is usually administered at the beginning of TACE procedure, after which a single dose of the embolisate is administered until the blood flow in the artery supplying the tumor ceases (Gruber-Rouh, Schmitt et al. 2018). The cTACE procedure is carried out with different chemotherapy and embolising materials depending on the clinic and the scheme used (Lencioni and Llovet 2010). The most commonly used embolizing material is Lipiodol (Vogl and Gruber-Rouh 2019). It plays a central role in cTACE as it is simultaneously used as a carrier substance for the chemotherapy drug, as an X-ray contrast agent for marking the tumor and as an embolizing material (Liapi and Geschwind 2011). The most widely used chemotherapeutic drug for cTACE worldwide is doxorubicin (Lencioni, Petruzzi et al. 2013) - although agents such as epirubicin, mitomycin, cisplatin, and miriplanin are also used (Vogl and Gruber-Rouh 2019). The different application of cTACE, with regard to the technique and the therapy plan, limits the comparability of cTACE (Lencioni, Petruzzi et al. 2013). The DEB-TACE procedure describes the intraarterial application of beads loaded with chemotherapeutically active substances in order to achieve a continuous release of these substances in (Vogl and Gruber-Rouh 2019). These beads are available in different sizes and, in contrast to cTACE, lead to a longer dwell of the chemotherapeutic agent in the tumor, with at the same time less systemic effects (Poon, Tso et al. 2007, Varela, Real et al. 2007, Vogl and Gruber-Rouh 2019). This is due to the lack of a time gap between the application of the chemotherapeutic agent and the embolisate as the beads act simultaneously as both thereby making an additional application of embolizing substances unnecessary. DC Beads ${ }^{\circledR}$ (non-biodegradable, polyvinyl alcohol-laden microspheres loaded with doxorubicin) are used most commonly for performing DEB-TACE procedures (Song and Kim 2017). Due to the lower plasma concentration of the chemotherapeutic agent in a DEB-TACE, significantly fewer drug-related adverse reactions could already be observed compared to cTACE (Varela, Real et al. 2007, Lencioni, de Baere et al. 2012). Nevertheless, the superiority of DEB-TACE over CTACE continues to be questioned due to insufficient randomized controlled studies (Facciorusso 2018). The most modern variant of TACE uses more biodegradable particles (degradable starch microspheres $=$ DSM), such as EmboCept ${ }^{\circledR}$ S particles (Caine, Carugo et al. 2017). As DSM-TACE is a recent development, it has been the topic of a few studies, some of which found both a favourable secondary level profile and a sufficient effectiveness of biodegradable particles in TACE (Kirchhoff, Bleck et al. 2007, Orlacchio, Chegai et al. 2015, Schicho, Pereira et al. 2017). However, data comparing the 
efficacy of the different TACE methods used in the bridging to transplant with those used in the palliative collective are rare. Here, we retrospectively assessed and compared the clinical safety and efficiency of the TACE variants used for bridging to transplant and in palliative procedures in HCC patients.

Although the results of sorafenib therapy in combination with other therapies, such as TACE, were positive in various meta-analyses (time-to-progress (TTP)), they were less so for overall survival (Zeng, Lv et al. 2016, Li, Zhao et al. 2018, Wang, Zhao et al. 2018). As a multikinase inhibitor, sorafenib interferes with the proliferation mechanism of tumor cells and their angiogenesis while increasing apoptosis (Chang, Adnane et al. 2007). However, due to its systemic application, as opposed to the local application within the framework of a TACE, side effects such as diarrhea, nausea, vomiting, and the hand-foot-skin syndrome ensue (Li, Gao et al. 2015).

\section{Materials And Methods}

\section{Study design}

The retrospective cohort study was conducted in a tertiary care center (Heidelberg University Hospital) and was approved by the institutional review board (IRB). Data collection was based on chart review of patients with established diagnosis of HCC, based on the EASL (European Association for the Study of the Liver) criteria, who had undergone at least one TACE procedure as a therapy for HCC between 2008 and 2017 in our center. In this period, 148 patients with HCC underwent 492 completed TACE procedures (158 for bridging to transplant; 334 for palliative treatment; Fig 1). Indication for TACE procedure was defined by multidisciplinary tumor board. The board's treatment approach followed the current EASLEORTC (European Organization for Research and Treatment of Cancer) Clinical Practice Guidelines (2012) in patients who had unresectable lesions and for whom other ablative therapies were not suitable. Patients who had been diagnosed with BCLC (Barcelona Clinic Liver Cancer) score (stage A, C, or D, but were unable or unwilling to receive the proposed therapy (e.g. LT, radiofrequency ablation (RFA), sorafenib) were also eligible for TACE therapy. For patients on the LT list, TACE was considered a standard bridging treatment. All decisions on the type of TACE treatment and modality of beads (CTACE vs. DSM-TACE or DEB-TACE vs. DSM-TACE) to be used in the patients were at the interventionalist's discretion.

\section{Subgroup definition}

Each TACE procedure of the included patients was categorized into two different subgroups, depending on their treatment plan at the time of TACE therapy: bridging to transplant or palliative therapy. Both collectives were split up into the different TACE methods: CTACE, DEB-TACE, and DSM-TACE. Within the palliative collective 244 DEB-TACE, 28 CTACE, and 62 DSM-TACE procedures were performed. In the bridging cohort 104 DEB-TACE, 32 cTACE, and 22 DSM-TACE procedures were conducted. The bridging to LT dataset included all interventions in which patients were enrolled on the transplant waiting list at the time of TACE, regardless of whether the LT was performed afterwards. The palliative dataset consisted of interventions performed in patients who did not meet the criteria for a LT at the time of TACE. 


\section{Statistics}

Statistical analysis was performed by using the SPSS-25 software (IBM, Germany). The two-tailed chisquared test was employed to compare the categorical data from different TACE variants used in the bridging and palliative datasets. Statistical comparative calculation between the subgroups for continuous endpoints was performed using the Kruskal-Wallis test. Statistical significance was set at $p$ value $<0.05$ in two-tailed tests. Categorial endpoints in the study were clinical symptoms such as nausea, vomiting, abdominal pain, fever, antibiotic treatment, rise of transaminases, and period of hospitalization.

\section{Results}

\section{Patient characteristics at TACE procedures}

A total of 492 TACE sessions were included in this study (158 bridging/ 334 palliative TACE sessions). As expected, due to listing criteria, patients in the bridging cohort were younger, had limited tumor spread, and different tumor properties, such as less frequent portal or hepatic vein infiltration and no extrahepatic tumor manifestation. The median age at the time of the various TACE procedures in the curative collective was about 58 years, whereas the median age in patients treated with palliative care was about 68 years at the time of the TACE session.

Similarly, the TACE collectives differed in terms of the number of tumorous lesions. Most patients showed multilocular HCC findings in both the curative and palliative collectives at the time of a TACE procedure. The maximum diameter of the HCC lesions at the time of a TACE session also differed significantly within both collectives. Patients undergoing TACE in palliative intent had a median lesion size that was twice as large in diameter as that in the bridging cohort.

Conventional TACE was performed more than twice as often in the curative cohort as it was in the palliative intent. However, the DEB-TACE and DSM-TACE procedures were carried out more frequently in the palliative intent cohort than in the curative one. Also noticeable was a significantly more frequent discontinuation of therapy due to adverse drug reactions/adverse events (AE) or death. There was no discontinuation of therapy due to AE or death in the bridging cohort. In the palliative collective, adverse or general reactions, which included both laboratory chemical and image morphological abnormalities after TACE as well as subjective and indirect parameters, occurred in all TACE variants with a relative frequency of over $90 \%$. The therapy was discontinued due to AE or death in $21.9 \%$ of all cases.

\section{Results in the palliative dataset}

A total of 244 procedures were carried out using the eluting beads as the active ingredient. We found that 28 sessions were conducted using cTACE with Carboplatin or Doxorubicin as the chemotherapeutic agent in combination with Lipiodol, which is only half as common as that in the bridging dataset and 62 TACE sessions were conducted using DSM-TACE. In the palliative group, 73 (21.9\%) TACE sessions were performed in patients who finally discontinued TACE therapy (and received no further local therapy) 
because of $A E$ or death, whereas in the bridging dataset none of the patients discontinued the TACE therapy (Table 2).

\section{Clinical side effects}

Patients receiving cTACE were significantly more likely (22\%) to report post-interventional nausea than patients treated with DEB-TACE $(8.1 \%)$ or DSM-TACE (4.9\%; Kruskal Wallis Test: $p=0.025$; see Table 3$)$. Although the occurrence of post-interventional abdominal pain did not reveal a significant difference in the various TACE variants, it is nevertheless noticeable that this undesirable drug effect also occurred most frequently after cTACE treatments in about $41 \%$ of the cases (Table 3 ). The same applies to the occurrence of post-interventional fever, as well as vomiting, and increase in transaminases after the CTACE session. Vascular complications, such as thrombosis or fistulas, did not occur after CTACE, whereas these could be observed sporadically after both DSM-TACE and DEB-TACE procedures. Antibiotic treatment due to an increased post-interventional CRP (c-reactive protein) was observed in about 18-19\% of all TACE procedures, regardless of which TACE variant was used.

\section{Laboratory effects}

Similarly, some post-interventional laboratory values differed to a significant extent depending on which TACE variant was used. This includes, for example, the post-interventional increase in creatinine, which was observed to be highest after CTACE $(\Delta 0.17$; Table 3$)$. Nevertheless, this is conditional to the amount of injected contrast agent, what was not analyzed. Definitive acute or chronic renal failure was not observed yet.

It was significantly more likely for a five-times increase above the upper normal limit ( $>5 x$ ULN) in the alanine transaminase (ALT) levels of patients following a cTACE procedure (36\%; $p=0.001)$. This was neither the case for aspartate transaminase (AST) increase nor for AST > 5x ULN.

\section{Period of hospitalization}

Furthermore, the median hospital stay after a DEB-TACE and a DSM TACE procedure was about $4 \mathrm{~d}$, whereas patients who underwent CTACE spent $5 \mathrm{~d}$ in hospital. Nevertheless, these differences reached statistical significance in the Kruskal-Wallis test $(p=0.02$; Table 3$)$.

\section{Results in the bridging dataset}

Table 4 lists the clinical outcome parameters depending on the TACE variant that was performed in the bridging dataset. In the curative collective, 104 procedures were carried out using active ingredient-eluting beads (DEB-TACE). A total of 32 sessions were conducted using CTACE and 22 using biodegradable particles (DSM-TACE).

\section{Clinical side effects}


Patients receiving cTACE treatments were more likely to report post-interventional nausea/vomiting and abdominal pain than those treated with DEB-TACE or DSM-TACE. In contrast, post-interventional fever was reported more frequently in patients receiving DSM-TACE (9.1\%). Antibiotic treatment due to an increased post-interventional CRP was observed in about 33-38 \% of all TACE procedures, regardless of which TACE variant was used.

\section{Laboratory effects}

There were no significant differences in the laboratory-determined increase of transaminases or the increase in creatinine levels between the different TACE procedures.

\section{Period of hospitalization}

Median hospital stay in all TACE groups was about $4 \mathrm{~d}$. Therefore, the period of hospitalization revealed no significance in the Kruskal-Wallis test $(p=0.688)$.

\section{Discussion}

The determination of the most acceptable and prognostically most favorable TACE procedure depending on the patient's condition and the treatment indication is a central point in the therapy of patients with HCC. In this study, significant differences were observed for the bridging TACE collective in terms of postinterventional $A E$ (clinical or laboratory $A E$ ), tumor response, and period of hospitalization. Nevertheless, this study has some limitations due to patient cohorts (bridging vs. palliative collective) and due to variant TACE procedures (different particle size, different area of embolization, amount of embolisate, selective vs. unselective TACE).

As already expected, patient cohorts are heterogeneous which is consistent with intend of curative respectively palliative therapy concept. Comparing the different TACE procedures, number of cTACE procedures is less in comparison to the amount of DEB- and DSM-TACE. There might be a selection bias using c-TACE/DEB-TACE in fitter patients and DSM-TACE in cases of advanced tumor size.

\section{Bridging TACE cohort}

The safety of the various TACE variants for the curative TACE collective or for patients receiving TACE as bridging therapy has so far been investigated to an insufficient extent. Although various studies have shown the evidence of a superior side effect profile with regard to various parameters in a DEB-TACE procedure compared to that with cTACE, these studies were mostly related to patients with an advanced HCC or to a palliative therapy indication (Lammer, Malagari et al. 2010, Ferrer Puchol, la Parra et al. 2011, van Malenstein, Maleux et al. 2011, Recchia, Passalacqua et al. 2012, Golfieri, Giampalma et al. 2014, Kloeckner, Weinmann et al. 2015, Zou, Zhang et al. 2016, Lee, Jung et al. 2017, Song and Kim 2017, Melchiorre, Patella et al. 2018). After cTACE, an increase in abdominal pain, nausea, and vomiting was observed in our study, which, however, this did not reach significance. The post-interventional increase of 
liver enzymes such as AST and ALT did not offer a significant difference in the analysis of the curative collective. Nevertheless, the average ALT and AST levels after a DEB-TACE increased to a higher degree than those after cTACE. This is in contrast to previous studies which observed an increase in liver parameters mainly or to a higher extent after CTACE procedures (Lammer, Malagari et al. 2010, Recchia, Passalacqua et al. 2012, Golfieri, Giampalma et al. 2014). However, these studies do not separate TACE intervention into curative and palliative patient collectives. Since DSM-TACE is generally used in patients with a palliative purpose (Kirchhoff, Bleck et al. 2007, lezzi, Pompili et al. 2016, lezzi, Pompili et al. 2019), its adverse reactions in patients with curative intention has not been sufficiently investigated. Although Schicho et al. (2017), Gruber-Rouh et al. (2018), and Orlacchio et al. (2018) included patients who underwent DSM-TACE with curative intent in their studies, they did not analyze them separately for the occurance of AE (Schicho, Pereira et al. 2017, Gruber-Rouh, Schmitt et al. 2018, Orlacchio, Chegai et al. 2018). Orlacchio et al. (2015) investigated DSM-TACE procedures with a view to assessing their safety and potential side effects and compared these with other TACE procedures by undertaking a literature research and found that DSM-TACE provides a similar level of security compared to CTACE and DEBTACE for a curative collective, however, this requires further investigation due to the small number of cases examined in the study by Orlacchio et. al. (Orlacchio, Chegai et al. 2015). In contrast to previous studies, in our analysis of the curative collective, the DSM-TACE showed a significantly higher increase in creatinine levels after the procedure compared to that after treatment with other TACE variants (Table 4). The DSM-TACE procedure has been described as a tolerable and low-impact TACE variant, and is particularly suitable for patients with impaired hepatic function due to its low systemic mode of action (Niessen, Unterpaintner et al. 2014, Schicho, Pereira et al. 2017, Orlacchio, Chegai et al. 2018, lezzi, Pompili et al. 2019). As with the assessment of the various side effects, there are particularly no studies that take both factors into account: the curative indication along with the kind of TACE variant used. Although there are several studies that compare the effects of a cTACE procedure to those of a DEB-TACE one, they do not explicitly refer to TACE as a curative intention and therefore do not compare palliative and curative TACE procedures separately.

The effectiveness of a DSM-TACE in comparison with the other TACE variants has been studied only in a few studies, primarily without differentiation between the respective therapy indications (Kirchhoff, Bleck et al. 2007, Niessen, Unterpaintner et al. 2014, Gruber-Rouh, Schmitt et al. 2018). Similarly, Orlacchio et al. (2015) offered not only a comparable safety, but also a comparable effectiveness of a DSM-TACE compared to the other TACE variants in relation to the curative objective of therapy (Orlacchio, Chegai et al. 2015). Both studies seem to be correlated to our findings, but a definitive interpretation should be avoided due to the limited number of cases.

\section{Palliative TACE cohort}

In contrast to those in the curative TACE collective, several studies with comparative analyses between the different TACE variants have already been published in the palliative setting. Our data also compared the treatment intention between the different TACE variants. In our analysis, only CTACE showed a significantly more frequent occurrence of various post-interventional side effects. After CTACE, nausea 
was the most frequently reported side effect. In the palliative cohort, nausea was significantly more often reported in patients receiving CTACE $(p=0.025)$. This might be associated with the systemic effect of the chemotherapeutic substances used for cTACE e.g. doxorubicin. Other parameters such as abdominal pain, vomiting, and fever were also most common after CTACE, but did not reach significance in the statistical analysis. Similarly, creatinine was significantly increased in cTACE in comparison to other TACE variants. A significant post-interventional ALT increase (> 5x ALT) could also be observed more often after a cTACE procedure.

In addition, patients with a cTACE procedure spent on average a day longer in the hospital than the patients receiving a different TACE variant. A certain advantage of a DSM-TACE or a DEB-TACE over CTACE in terms of safety has already been identified in several studies (Lammer, Malagari et al. 2010, Ferrer Puchol, la Parra et al. 2011, van Malenstein, Maleux et al. 2011, Recchia, Passalacqua et al. 2012, Jang, Lee et al. 2015, Lee, Jung et al. 2017, Song and Kim 2017, Melchiorre, Patella et al. 2018). In most of these studies, the general comparison of CTACE and DEB-TACE was made, whereas the comparative assessment of all three TACE variants was hardly included in any study. Although our results showed no significance in terms of post-interventional AST or ALT levels, our higher AST and ALT values for CTACE on average compared to DEB-TACE are consistent with several studies that also observed a more pronounced increase in these parameters after CTACE (Lammer, Malagari et al. 2010, Sacco, Bargellini et al. 2011, Golfieri, Giampalma et al. 2014, Sacco, Tapete et al. 2017).

However, a direct comparison of DSM-TACE with the other TACE variants has not been made yet. Thus, an advantage of the DSM-TACE over other TACE variants in terms of the spectrum of side effects remains without clear evidence. The results in the palliative collective offer a certain advantage of the DSM-TACE and DEB-TACE procedures over a CTACE. Although the case numbers in the palliative collective are greater than those in the bridging collective, further large-scale studies are needed to detect a clear advantage of a particular TACE variant and to analyze the effectiveness and safety of different TACE variants depending on the respective therapy indications.

\section{Conclusions}

The treatment of patients suffering from HCC is also difficult to follow, even with currently more or less clear recommendations. The use of TACE therapy has already become a clear priority in the treatment of these patients, although the question of the therapy intention and the correct TACE variant for specific patient or tumor properties still has not been clarified clearly. Our aim was to identify significant differences in the different collectives (palliative versus curative), to assess the clinical outcome depending on the TACE variant used, and to assess the applicability of different classification systems in the respective collectives. Based on our descriptive analysis and the significant differences between the curative and palliative collectives, both in terms of patient characteristics and course parameters, further clinical decisions should be prognostic analyses and the applications of classification systems should always be carried out depending on the respective therapy indication. In the curative collective, all TACE variants proved to have a similarly safety with regard to AE studied, so that the preference of a particular 
TACE procedure cannot be specified. In the palliative collective, there was a tendency to perform cTACE in relation to the adverse reaction profile. However, with relatively small numbers of cases in the analysis of the various TACE variants, further studies are needed to make a definitive statement in this regard.

\section{Declarations}

Funding: None

Conflicts of Interest: The authors declare no conflicts of interest.

Ethics approval: Compliance with ethical standards. All procedures performed in studies involving human participants were in accordance with the ethical standards of the institutional and/or national research committee and with the 1964 Helsinki declaration and its later amendments or comparable ethical standards

Consent to participate: NA

Consent for publication: NA

Availability of data and material: All data for the study are provided along with the article

Code availability: NA

Author Contributions: MM functions as corresponding author. IM and MV contributed equally. JP, SDS, MK, AT, D-HC, CS, TL, UM, AM and KHW contributed as coauthors in the ranking mentioned above. Funding There was no financial support or funding for the study

\section{References}

1. Arii S, Yamaoka Y, Futagawa S, Inoue K, Kobayashi K, Kojiro M, Makuuchi M, Nakamura Y, Okita K, Yamada R (2000) Results of surgical and nonsurgical treatment for small-sized hepatocellular carcinomas: a retrospective and nationwide survey in Japan. The Liver Cancer Study Group of Japan. Hepatology. 32(6):1224-1229. https://doi.org/10.1053/jhep.2000.20456

2. Bruix J, Sherman M; Practice guidelines committee, American association for the study of liver diseases (2005) Management of hepatocellular carcinoma. Hepatology 42(5):1208-1236. https://doi.org/10.1002/hep.20933

3. Bruix J, Sherman M (2011) Management of hepatocellular carcinoma: an update. Hepatology 53(3):1020-1022. https://doi.org/10.1002/hep.24199

4. Cabibbo G, Enea M, Attanasio M, Bruix J, Craxì A, Cammà C (2010) A meta-analysis of survival rates of untreated patients in randomized clinical trials of hepatocellular carcinoma. Hepatology 51(4):1274-1283. https://doi.org/10.1002/hep.23485 
5. Caine M, Carugo D, Zhang X, Hill M, Dreher MR, Lewis AL (2017) Review of the Development of Methods for Characterization of Microspheres for Use in Embolotherapy: Translating Bench to Cathlab. Adv Healthc Mater 6(9). https://doi.org/10.1002/adhm.201601291

6. Chang YS, Adnane J, Trail PA, et al (2007) Sorafenib (BAY 43-9006) inhibits tumor growth and vascularization and induces tumor apoptosis and hypoxia in RCC xenograft models. Cancer Chemother Pharmacol 59(5):561-574. https://doi.org/10.1007/s00280-006-0393-4

7. Decaens T, Roudot-Thoraval F, Bresson-Hadni S, et al (2005) Impact of pretransplantation transarterial chemoembolization on survival and recurrence after liver transplantation for hepatocellular carcinoma. Liver Transpl 11(7):767-775. https://doi.org/10.1002/It.20418

8. EASL-EORTC (2012) clinical practice guidelines: management of hepatocellular carcinoma. J Hepatol 56(4):908-943. https://doi.org/10.1016/j.jhep.2011.12.001

9. Facciorusso A. (2018) Drug-eluting beads transarterial chemoembolization for hepatocellular carcinoma: Current state of the art. World J Gastroenterol 24(2):161-169.

https://doi.org/10.3748/wjg.v24.i2.161

10. Frenette CT, Osorio RC, Stark J, Fok B, Boktour MR, Guy J, Rhee J, Osorio RW (2014) Conventional TACE and drug-eluting bead TACE as locoregional therapy before orthotopic liver transplantation: comparison of explant pathologic response. Transplantation 98(7):781-7. https://doi.org/10.1097/tp.0000000000000121

11. Gruber-Rouh T, Schmitt C, Naguib NNN, Nour-Eldin NA, Eichler K, Beeres M, Vogl TJ (2018) Transarterial chemoembolization (TACE) using mitomycin and lipiodol with or without degradable starch microspheres for hepatocellular carcinoma: comparative study. BMC Cancer 18(1):188. https://doi.org/10.1186/s12885-018-4099-x

12. Golfieri R, Giampalma E, Renzulli M, et al (2014) Randomised controlled trial of doxorubicin-eluting beads vs conventional chemoembolisation for hepatocellular carcinoma. $\mathrm{Br} \mathrm{J}$ Cancer 111(2):255264. https://doi.org/10.1038/bjc.2014.199

13. lezzi R, Pompili M, Nestola M, et al (2016) Transarterial chemoembolization with degradable starch microspheres (DSM-TACE): an alternative option for advanced HCC patients? Preliminary results. Eur Rev Med Pharmacol Sci 20(13):2872-2877

14. lezzi R, Pompili M, Rinninella E, et al (2019) TACE with degradable starch microspheres (DSM-TACE) as second-line treatment in HCC patients dismissing or ineligible for sorafenib. Eur Radiol 29(3):1285-1292. https://doi.org/10.1007/s00330-018-5692-8

15. Ikai I, Arii S, Kojiro M, Ichida T, Makuuchi M, Matsuyama Y, Okita K, Omata M, Takayasu K, Yamaoka $Y(2004)$ Reevaluation of prognostic factors for survival after liver resection in patients with hepatocellular carcinoma in a Japanese nationwide survey. Cancer. 101(4):796-802. https://doi.org/10.1002/cncr.20426

16. Jang JH, Lee JW, Hong JT, Jin YJ (2015) Transarterial chemoembolization for hepatocellular carcinoma: an evidence-based review of its place in therapy. J Hepatocell Carcinoma 2:123-129. https://doi.org/10.2147/jhc.s44380 
17. Kirchhoff TD, Bleck JS, Dettmer A, et al (2007) Transarterial chemoembolization using degradable starch microspheres and iodized oil in the treatment of advanced hepatocellular carcinoma: evaluation of tumor response, toxicity, and survival. Hepatobiliary Pancreat Dis Int 6(3):259-266.

18. Kloeckner R, Weinmann A, Prinz F, dos Santos D, Ruckes C, Dueber C, Pitton MB (2015) Conventional transarterial chemoembolization versus drug-eluting bead transarterial chemoembolization for the treatment of hepatocellular carcinoma. BMC Cancer 15:465. https://doi.org/10.1186/s12885-015$1480-x$

19. Kollmann D, Selzner N, Selzner M (2017) Bridging to liver transplantation in HCC patients. Langenbecks Arch Surg 402(6):863-871. https://doi.org/10.1007/s00423-017-1609-2

20. Lammer J, Malagari K, Vogl T, et al (2010) Prospective randomized study of doxorubicin-eluting-bead embolization in the treatment of hepatocellular carcinoma: results of the PRECISION V study. Cardiovasc Intervent Radiol 33(1):41-52. https://doi.org/10.1007/s00270-009-9711-7

21. Lee IC, Huo TI, Huang YH, et al (2012) Transarterial chemoembolization can prolong survival for patients with metastatic hepatocellular carcinoma: a propensity score matching analysis. Hepatol Int 6(4):753-762. https://doi.org/10.1007/s12072-011-9322-7

22. Lee YK, Jung KS, Kim DY, et al (2017) Conventional versus drug-eluting beads chemoembolization for hepatocellular carcinoma: Emphasis on the impact of tumor size. J Gastroenterol Hepatol 32(2):487-96. https://doi.org/10.1111/jgh.13501

23. Lencioni R, de Baere T, Burrel M, et al (2012) Transcatheter treatment of hepatocellular carcinoma with Doxorubicin-loaded DC Bead (DEBDOX): technical recommendations. Cardiovasc Intervent Radiol 35(5):980-985. https://doi.org/10.1007/s00270-011-0287-7

24. Lencioni R, Llovet JM (2010) Modified RECIST (mRECIST) assessment for hepatocellular carcinoma. Semin Liver Dis 30(1):52-60. https://doi.org/10.1055/s-0030-1247132

25. Lencioni R, Llovet JM, Han G, et al (2016) Sorafenib or placebo plus TACE with doxorubicin-eluting beads for intermediate stage HCC: The SPACE trial. J Hepatol 64(5):1090-1098. https://doi.org/10.1016/j.jhep.2016.01.012

26. Lencioni R, Petruzzi P, Crocetti L (2013) Chemoembolization of hepatocellular carcinoma. Semin Intervent Radiol 30(1):3-11. https://doi.org/10.1055/s-0033-1333648

27. Li L, Zhao W, Wang M, Hu J, Wang E, Zhao Y, Liu L (2018) Transarterial chemoembolization plus sorafenib for the management of unresectable hepatocellular carcinoma: a systematic review and meta-analysis. BMC Gastroenterol 18(1):138. https://doi.org/10.1186/s12876-018-0849-0

28. Li Y, Gao ZH, Qu XJ (2015) The adverse effects of sorafenib in patients with advanced cancers. Basic Clin Pharmacol Toxicol 116(3):216-21. https://doi.org/10.1111/bcpt.12365

29. Liapi E, Geschwind JFH (2011) Transcatheter arterial chemoembolization for liver cancer: is it time to distinguish conventional from drug-eluting chemoembolization? Cardiovasc Intervent Radiol 34(1):37-49. https://doi.org/10.1007/s00270-010-0012-y

30. Llovet JM, Bruix J (2003) Systematic review of randomized trials for unresectable hepatocellular carcinoma: Chemoembolization improves survival. Hepatology. 37(2):429-442. 
https://doi.org/10.1053/jhep.2003.50047

31. Llovet JM, Bustamante J, Castells A, Vilana R, Ayuso MdelC, Sala M, Brú C, Rodés J, Bruix J (1999) Natural history of untreated nonsurgical hepatocellular carcinoma: rationale for the design and evaluation of therapeutic trials. Hepatology 29(1):62-67. https://doi.org/10.1002/hep.510290145

32. Llovet JM, Di Bisceglie AM, Bruix J, et al (2008) Design and endpoints of clinical trials in hepatocellular carcinoma. J Natl Cancer Inst 100(10):698-711. https://doi.org/10.1093/jnci/djn134

33. Llovet JM, Schwartz M, Mazzaferro V (2005) Resection and liver transplantation for hepatocellular carcinoma. Semin Liver Dis. 25(2):181-200. https://doi.org/10.1055/s-2005-871198

34. Majno PE, Adam R, Bismuth H, Castaing D, Ariche A, Krissat J, Perrin H, Azoulay D (1997) Influence of preoperative transarterial lipiodol chemoembolization on resection and transplantation for hepatocellular carcinoma in patients with cirrhosis. Ann Surg 226(6):688-701. https://dx.doi.org/10.1097\%2F00000658-199712000-00006

35. Marrero JA, Fontana RJ, Barrat A, Askari F, Conjeevaram HS, Su GL, Lok AS (2005) Prognosis of hepatocellular carcinoma: comparison of 7 staging systems in an American cohort. Hepatology 41(4):707-716. https://doi.org/10.1002/hep.20636

36. Melchiorre F, Patella F, Pescatori L, et al (2018) DEB-TACE: a standard review. Future Oncol 14(28):2969-2984. https://doi.org/10.2217/fon-2018-0136

37. Niessen C, Unterpaintner E, Goessmann H, Schlitt HJ, Mueller-Schilling M, Wohlgemuth WA, Stroszczynski C, Wiggermann P (2014) Degradable starch microspheres versus ethiodol and doxorubicin in transarterial chemoembolization of hepatocellular carcinoma. J Vasc Interv Radiol 25(2):240-247. https://doi.org/10.1016/j.jvir.2013.10.007

38. Okuda K, Ohtsuki T, Obata H, Tomimatsu M, Okazaki N, Hasegawa H, Nakajima Y, Ohnishi K (1985) Natural history of hepatocellular carcinoma and prognosis in relation to treatment. Study of 850 patients. Cancer 56(4):918-928. https://doi.org/10.1002/1097-0142(19850815)56:4\%3C918::aidcncr2820560437\%3E3.0.co;2-e

39. Orlacchio A, Chegai F, Francioso S, Merolla S, Monti S, Angelico M, Tisone G, Mannelli L (2018) Repeated transarterial chemoembolization with degradable starch microspheres (DSMs-TACE) of unresectable hepatocellular carcinoma: A prospective pilot study. Curr Med Imaging Rev 14(4):637645. https://doi.org/10.2174/1573405613666170616123657

40. Orlacchio A, Chegai F, Merolla S, Francioso S, Giudice CD, Angelico M, Tisone G, Simonetti G (2015) Downstaging disease in patients with hepatocellular carcinoma outside up-to-seven criteria: Strategies using degradable starch microspheres transcatheter arterial chemo-embolization. World J Hepatol 7(12):1694-1700. https://doi.org/10.4254/wjh.v7.i12.1694

41. Porrett PM, Peterman H, Rosen M, Sonnad S, Soulen M, Markmann JF, Shaked A, Furth E, Reddy KR, Olthoff K (2006) Lack of benefit of pre-transplant locoregional hepatic therapy for hepatocellular cancer in the current MELD era. Liver Transpl 12(4):665-673. https://doi.org/10.1002/lt.20636

42. Puchol MDF, la Parra C, Esteban E, Vano M, Forment M, Vera A, Cosín O (2011) Comparison of doxorubicin-eluting bead transarterial chemoembolization (DEB-TACE) with conventional 
transarterial chemoembolization (TACE) for the treatment of hepatocellular carcinoma. Radiologia 53(3):246-253. https://doi.org/10.1016/j.rx.2010.07.010

43. Recchia F, Passalacqua G, Filauri P, Doddi M, Boscarato P, Candeloro G, Necozione S, Desideri G, Rea $S$ (2012) Chemoembolization of unresectable hepatocellular carcinoma: Decreased toxicity with slow-release doxorubicineluting beads compared with lipiodol. Oncol Rep 27(5):1377-1383. https://doi.org/10.3892/or.2012.1651

44. Sacco R, Bargellini I, Bertini M, et al (2011) Conventional versus doxorubicin-eluting bead transarterial chemoembolization for hepatocellular carcinoma. J Vasc Interv Radiol 22(11):1545-52. https://doi.org/10.1016/j.jvir.2011.07.002

45. Sacco R, Tapete G, Simonetti N, Sellitri R, Natali V, Melissari S, Cabibo G, Biscaglia L, Bresci G, Giacomelli $L$ (2017) Transarterial chemoembolization for the treatment of hepatocellular carcinoma: a review. J Hepatocell Carcinoma 4:105-10. https://doi.org/10.2147/jhc.s103661

46. Schicho A, Pereira PL, Haimerl M, Niessen C, Michalik K, Beyer LP, Stroszczynski C, Wiggerman P (2017) Transarterial chemoembolization (TACE) with degradable starch microspheres (DSM) in hepatocellular carcinoma (HCC): multi-center results on safety and efficacy. Oncotarget 8(42):7261320. https://doi.org/10.18632/oncotarget.19997

47. Song JE, Kim DY (2017) Conventional vs drug-eluting beads transarterial chemoembolization for hepatocellular carcinoma. World J Hepatol 9(18):808-14.

https://dx.doi.org/10.4254\%2Fwjh.v9.i18.808

48. Takayasu K, Arii S, Ikai I, et al (2006) Prospective cohort study of transarterial chemoembolization for unresectable hepatocellular carcinoma in 8510 patients. Gastroenterology 131(2):461-469. https://doi.org/10.1053/j.gastro.2006.05.021

49. van Malenstein H, Maleux G, Vandecaveye V, Heye S, Laleman W, van Pelt J, Vaninbroukx J, Nevens F, Verslype $C$ (2011) A randomized phase II study of drug-eluting beads versus transarterial chemoembolization for unresectable hepatocellular carcinoma. Onkologie 34(7):368-376. https://doi.org/10.1159/000329602

50. Varela M, Real MI, Burrel M, et al (2007) Chemoembolization of hepatocellular carcinoma with drug eluting beads: efficacy and doxorubicin pharmacokinetics. J Hepatol 46(3):474-481. https://doi.org/10.1016/j.jhep.2006.10.020

51. Vogl TJ, Gruber-Rouh T (2019) HCC: Transarterial Therapies-What the Interventional Radiologist Can Offer. Dig Dis Sci 64(4):959-967. https://doi.org/10.1007/s10620-019-05542-5

52. Wang YY, Zhao XH, Ma L, Ye JZ, Wu FX, Tang J, You XM, Xiang BD, Li LQ (2018) Comparison of the ability of Child-Pugh score, MELD score, and ICG-R15 to assess preoperative hepatic functional reserve in patients with hepatocellular carcinoma. J Surg Oncol 118(3):440-445. https://doi.org/10.1002/jso. 25184

53. Zangos S, Eichler K, Balzer JO, et al (2007) Large-sized hepatocellular carcinoma (HCC): a neoadjuvant treatment protocol with repetitive transarterial chemoembolization (TACE) before 
percutaneous MR-guided laser-induced thermotherapy (LITT). Eur Radiol 17(2):553-563.

https://doi.org/10.1007/s00330-006-0343-x

54. Zeng J, Lv L, Mei ZC (2016) Efficacy and safety of transarterial chemoembolization plus sorafenib for early or intermediate stage hepatocellular carcinoma: A systematic review and meta-analysis of randomized controlled trials. Clin Res Hepatol Gastroenterol 40(6):688-697. https://doi.org/10.1016/j.clinre.2016.04.006

55. Zou JH, Zhang L, Ren ZG, Ye SL (2016) Efficacy and safety of cTACE versus DEB-TACE in patients with hepatocellular carcinoma: a meta-analysis. J Dig Dis 17(8):510-517. https://doi.org/10.1111/1751-2980.12380

\section{Tables}

Table 1: Baseline characteristics of the bridging and palliative datasets 


\begin{tabular}{|c|c|c|c|c|c|c|}
\hline \multicolumn{2}{|l|}{ Baseline characteristics } & \multicolumn{2}{|l|}{$\begin{array}{l}\text { Bridging } \\
\text { dataset }\end{array}$} & \multicolumn{3}{|l|}{$\begin{array}{l}\text { Palliative } \\
\text { dataset }\end{array}$} \\
\hline & & $\mathrm{N}(\%)$ & $\begin{array}{l}\text { Total } \\
(\mathrm{N})\end{array}$ & $\mathrm{N}(\%)$ & $\begin{array}{l}\text { Total } \\
\text { (N) }\end{array}$ & $\mathrm{p}$ \\
\hline Number of patients & & $61(100)$ & & $87(100)$ & & \\
\hline $\begin{array}{l}\text { Age (at first TACE). years } \\
\text { (median. range) }\end{array}$ & & $58(28-69)$ & 61 & $68(49-88)$ & 87 & $\dot{0} 001$ \\
\hline \multirow[t]{2}{*}{ Gender } & Male & $47(77 . .0)$ & 61 & $71(81.6)$ & 87 & 0.497 \\
\hline & Female & $14(23.0)$ & & $16(18.4)$ & & \\
\hline \multirow[t]{4}{*}{ BCLC stage } & $A$ & $40(65.6)$ & 61 & $17(19.5)$ & 87 & $\dot{0} 001$ \\
\hline & B & $9(14.8)$ & & $34(39.1)$ & & \\
\hline & C & $4(6.6)$ & & $29(33.3)$ & & \\
\hline & $\mathrm{D}$ & $8(13.1)$ & & $7(8.0)$ & & \\
\hline \multirow[t]{3}{*}{ Child-Pugh class } & $A$ & $32(52.5)$ & 61 & $55(63.2)$ & 87 & 0.370 \\
\hline & B & $21(34.4)$ & & 25 (28.7) & & \\
\hline & $\mathrm{C}$ & $8(13.1)$ & & $7(8.0)$ & & \\
\hline Cirrhosis & & $58(95.1)$ & 61 & $68(78.2)$ & 87 & 0.004 \\
\hline \multirow[t]{2}{*}{ Number of tumor nodules } & $\leq 1$ & $28(45.9)$ & 61 & $25(28.7)$ & 87 & 0.032 \\
\hline & $>1$ & $33(54.1)$ & & $62(71.3)$ & & \\
\hline $\begin{array}{l}\text { Maximal diameter, } \mathrm{cm} \\
\text { (median, range) }\end{array}$ & - & $\begin{array}{l}2.5(1.2- \\
4.9)\end{array}$ & 61 & $\begin{array}{l}4.7(1.0- \\
16.5)\end{array}$ & 87 & $\hat{0} .001$ \\
\hline AFP, $\mathrm{ng} / \mathrm{ml}$ & $<400$ & 55 (93.2) & 59 & 70 (82.4) & 85 & 0.058 \\
\hline
\end{tabular}




\begin{tabular}{|c|c|c|c|c|c|c|}
\hline & $\geq 400$ & $4(6.8)$ & & 15 (17.6) & & \\
\hline Portal vein thrombosis & - & $0(0.0)$ & 61 & $7(8.0)$ & 87 & 0.023 \\
\hline Vena cava thrombosis & - & $0(0.0)$ & 61 & $1(1.1)$ & 87 & 0.401 \\
\hline Liver vein thrombosis & - & $0(0.0)$ & 61 & $2(2.3)$ & 87 & 0.233 \\
\hline Extrahepatic spread & - & $0(0.0)$ & 61 & $8(9.2)$ & 87 & 0.015 \\
\hline Esophageal varices & - & $40(65.6)$ & 61 & $36(41.1)$ & 87 & 0.004 \\
\hline \multirow[t]{7}{*}{ Etiology } & Viral & $23(37.7)$ & 61 & $33(37.9)$ & 87 & 0.270 \\
\hline & $\begin{array}{l}\text { Alcohol } \\
\text { abuse }\end{array}$ & 19 (31.1) & & $26(29.9)$ & & \\
\hline & $\begin{array}{l}\text { Viral + } \\
\text { alcohol }\end{array}$ & $7(11.5)$ & & $6(6.9)$ & & \\
\hline & $\mathrm{NASH}$ & $0(0)$ & & $2(2.3)$ & & \\
\hline & Cryptogenic & $4(6.6)$ & & $13(14.9)$ & & \\
\hline & Autoimmune & $4(6.6)$ & & $1(1.1)$ & & \\
\hline & Others & $4(6.6)$ & & $6(6.9)$ & & \\
\hline
\end{tabular}

TACE $=$ transarterial chemoembolization; $\mathrm{BCLC}=$ Barcelona Clinic Liver Cancer $; \mathrm{AFP}=$ alpha fetoprotein Table 2: Comparison between transarterial chemoembolization (TACE) therapy characteristics in the bridging vs. palliative datasets 


\begin{tabular}{|c|c|c|c|c|c|c|}
\hline \multirow{2}{*}{$\begin{array}{l}\text { Characteristics of TACE } \\
\text { Therapy }\end{array}$} & & \multicolumn{2}{|l|}{$\begin{array}{l}\text { Bridging } \\
\text { dataset }\end{array}$} & \multicolumn{3}{|l|}{$\begin{array}{l}\text { Palliative } \\
\text { dataset }\end{array}$} \\
\hline & & $\mathrm{N}(\%)$ & $(\mathrm{N})$ & $\mathrm{N}(\%)$ & $(\mathrm{N})$ & $\mathrm{p}$ \\
\hline Number of patients & & $61(100)$ & & $87(100)$ & & \\
\hline $\begin{array}{l}\text { Number of TACE procedures in } \\
\text { general }\end{array}$ & & $158(100)$ & & $\begin{array}{l}334 \\
(100)\end{array}$ & 561 & \\
\hline $\begin{array}{l}\text { Completed TACE-procedures per } \\
\text { patient (median, range) }\end{array}$ & & $3(1-10)$ & 61 & $3(1-10)$ & 87 & 0.072 \\
\hline $\begin{array}{l}\text { Time from first completed to last } \\
\text { completed TACE (except patients } \\
\text { with only one TACE-procedure), } \\
\text { months }\end{array}$ & & $\begin{array}{l}3.5(0.9- \\
35.0)\end{array}$ & 48 & $\begin{array}{l}8.0(0.9- \\
58.6)\end{array}$ & 71 & 0.009 \\
\hline (median, range) & & & & & & \\
\hline Change to systemic therapy & & $7(11.5)$ & 61 & $10(11.5)$ & 87 & 0.997 \\
\hline Progress & & $22(36.1)$ & 61 & $59(67.8)$ & 87 & $\hat{0.001}$ \\
\hline $\begin{array}{l}\text { Time to progress, months } \\
\text { (median, } 95 \% \mathrm{Cl} \text { ) }\end{array}$ & & $\begin{array}{l}13.8(11.5- \\
16.2)\end{array}$ & 61 & $\begin{array}{l}9.7(6.0- \\
13.4)\end{array}$ & 87 & 0.054 \\
\hline \multirow[t]{4}{*}{ Category of TACE } & DEB & $39(63.9)$ & 61 & $55(63.2)$ & 87 & 0.058 \\
\hline & Conventional & $9(14.8)$ & & $3(3.4)$ & & \\
\hline & Biodegrad. & $5(8.2)$ & & $11(12.6)$ & & \\
\hline & others & $8(13.1)$ & & $18(20.7)$ & & \\
\hline TACE therapy discontinuation & & $21(34.4)$ & 61 & $79(90.8)$ & 87 & $\hat{0.001}$ \\
\hline Reason of therapy & Death & $0(0)$ & 21 & $12(15.2)$ & 79 & 0.047 \\
\hline
\end{tabular}


discontinuation

Other therapy received after

therapy discontinuation

Additional TACE received despite progress

$\begin{array}{lll}\text { Progress } & 6(28.6) & 24(30.4) \\ \text { Technical } & 9(42.9) & 14(17.7) \\ \text { AE } & 0(0) & 7(8.9)\end{array}$

Others

$6(28.6)$

$22(27.8)$

\begin{tabular}{|c|c|c|c|c|c|c|}
\hline progiess & & $(81.1)^{18}$ & $<$ & $46(78.0)$ & 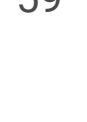 & 0.705 \\
\hline \multirow[t]{5}{*}{ Therapy type after TACE } & Sorafenib & $6(37.5)$ & 16 & $26(57.8)$ & 45 & 0.523 \\
\hline & SIRT & $1(6.3)$ & & $3(6.7)$ & & \\
\hline & RFA & $3(18.8)$ & & $3(6.7)$ & & \\
\hline & IRE & $2(12.5)$ & & $3(6.7)$ & & \\
\hline & Others/var. & $4(25.0)$ & & $10(22.2)$ & & \\
\hline Deceased & & $19(31.1)$ & 61 & $55(63.2)$ & 87 & $\hat{0.001}$ \\
\hline $\begin{array}{l}\text { Median survival time after first } \\
\text { completed TACE-procedure } \\
\text { (median, } 95 \% \mathrm{Cl} \text { ) }\end{array}$ & & $\underset{\left({ }^{*}\right)}{\text { Not reached }}$ & 61 & $\begin{array}{l}22.5 \\
(15.7- \\
29.4)\end{array}$ & 87 & <. 001 \\
\hline
\end{tabular}

SIRT = Selective Internal Radiotherapy; RFA = Radio Frequency Ablation; IRE = irreversible electroporation Table 3: Outcome parameters in the palliative dataset 


\begin{tabular}{|c|c|c|c|c|c|}
\hline Outcome parameters & & DEB-TACE & cTACE & DSM-TACE & \\
\hline Palliative dataset & & $\mathrm{N}(\%)$ & $\mathrm{N}(\%)$ & $N(\%)$ & $\mathrm{P}$ \\
\hline Number of TACE sessions & & $244(100)$ & $28(100)$ & $62(100)$ & \\
\hline Adverse events in general & & $211(89.8)$ & $28(100)$ & $60(96.8)$ & 0.052 \\
\hline Abdominal pain & & $65(27.8)$ & $11(40.7)$ & $11(18.0)$ & 0.076 \\
\hline Nausea & & $19(8.1)$ & $6(22.2)$ & $3(4.9)$ & 0.025 \\
\hline Fever & & $43(18.4)$ & $6(22.2)$ & $10(16.4)$ & 0.808 \\
\hline Vomiting & & $7(3.0)$ & $2(7.4)$ & $0(0)$ & 0.142 \\
\hline \multirow[t]{2}{*}{ Increase of AST } & & $181(83.0)$ & $19(95.0)$ & $49(80.3)$ & 0.307 \\
\hline & $\begin{array}{l}\text { Increase in UI/I } \\
\text { (Median, SD) }\end{array}$ & $\begin{array}{l}77.0 \\
(308.3)\end{array}$ & $\begin{array}{l}232.0 \\
(248.1)\end{array}$ & $\begin{array}{l}130.0 \\
(318.9)\end{array}$ & 0.053 \\
\hline Increase of AST >5 x ULN & & $66(28.0)$ & $12(50.0)$ & $20(32.8)$ & 0.075 \\
\hline \multirow[t]{2}{*}{ Increase of ALT } & & $171(78.8)$ & $19(95.0)$ & $46(75.4)$ & 0.167 \\
\hline & $\begin{array}{l}\text { Increase in UI/I } \\
\text { (Median, SD) }\end{array}$ & $\begin{array}{l}39.0 \\
(217.0)\end{array}$ & $\begin{array}{l}92.0 \\
(319.3)\end{array}$ & $\begin{array}{l}52.5 \\
(114.5)\end{array}$ & 0.057 \\
\hline Increase of ALT $>5 \times$ ULN & & $24(9.9)$ & $9(36.0)$ & $7(11.3)$ & 0.001 \\
\hline Portal vein fistula & & $9(3.8)$ & $0(0)$ & $1(1.7)$ & 0.441 \\
\hline GI-Ulcer & & $4(1.7)$ & $0(0)$ & $0(0)$ & 0.482 \\
\hline Cholecystitis & & $2(0.8)$ & $0(0)$ & $2(3.4)$ & 0.238 \\
\hline Abscess & & $7(3.0)$ & $1(3.7)$ & $0(0)$ & 0.389 \\
\hline \multirow[t]{3}{*}{ Increase of Creatinine } & & $124(56.9)$ & $12(63.2)$ & $41(68.3)$ & 0.263 \\
\hline & $\begin{array}{l}\text { Increase in } \\
\mathrm{mg} / \mathrm{dl}\end{array}$ & $\begin{array}{l}0.08 \\
(0.22)\end{array}$ & $0.17(1.54)$ & $0.07(0.09)$ & 0.022 \\
\hline & (Median. SD) & & & & \\
\hline \multirow[t]{4}{*}{ Antibiotic treatment $(\mathrm{AB})$} & Periinterv. & $23(9.8)$ & $4(14.8)$ & $5(8.2)$ & 0.158 \\
\hline & Postinterv. & $10(4.3)$ & $4(14.8)$ & $1(1.6)$ & \\
\hline & After CRP $\uparrow$ & $81(34.6)$ & $9(33.3)$ & $23(37.7)$ & \\
\hline & Without $A B$ & $120(51.3)$ & $10(37.0)$ & $32(52.5)$ & \\
\hline
\end{tabular}




\begin{tabular}{|c|c|c|c|c|c|}
\hline \multicolumn{2}{|l|}{ Analgesic therapy post TACE } & \multirow{2}{*}{$\begin{array}{l}201(82.7) \\
4(2-25)\end{array}$} & \multirow{2}{*}{$\begin{array}{l}26(92.9) \\
5(3-15)\end{array}$} & \multirow{2}{*}{$\begin{array}{l}47(78.3) \\
4(2-28)\end{array}$} & \multirow{2}{*}{$\begin{array}{l}0.243 \\
0.020\end{array}$} \\
\hline $\begin{array}{l}\text { Hospital stay, days (median, } \\
\text { range) }\end{array}$ & & & & & \\
\hline \multirow[t]{4}{*}{ Staging 4-6 wk after TACE } & PR & $25(10.2)$ & $6(21.4)$ & $7(11.3)$ & \multirow[t]{4}{*}{0.242} \\
\hline & SD & $156(63.9)$ & $14(50.0)$ & $43(69.4)$ & \\
\hline & PD & $55(22.5)$ & $6(21.4)$ & $8(12.9)$ & \\
\hline & No staging & $8(3.3)$ & $2(7.1)$ & $4(6.5)$ & \\
\hline
\end{tabular}

TACE = transarterial chemoembolization; CTACE = conventional transarterial chemoembolization; DEMTACE = drug-eluting bead transarterial chemoembolization; DSM-TACE = transarterial chemoembolization with degradable starch microspheres; $A S T$ = aspartate transaminase; $A L T$ = alanine transaminase; $S D=$ stable disease; $\mathrm{CR}=$ complete remission, $\mathrm{PR}=$ partial remission, $\mathrm{SD}=$ stable disease, $\mathrm{PD}=$ progressive disease

Table 4: Outcome parameters for the bridging dataset 


\begin{tabular}{|c|c|c|c|c|c|}
\hline Outcome parameters & & DEB-TACE & cTACE & DSM-TACE & \\
\hline bridging dataset & & $\mathrm{N}(\%)$ & $\mathrm{N}(\%)$ & $\mathrm{N}(\%)$ & $\mathrm{p}$ \\
\hline Number of TACE sessions & & $104(100)$ & $32(100)$ & $22(100)$ & \\
\hline Adverse events in general & & $90(90.9)$ & $29(93.5)$ & $21(95.5)$ & 0.732 \\
\hline Abdominal pain & & $33(32.7)$ & $11(34.4)$ & 7 (31.8) & 0.977 \\
\hline Nausea & & $11(10.9)$ & $6(18.8)$ & $3(13.6)$ & 0.510 \\
\hline Fever & & $8(7.9)$ & $2(6.3)$ & $2(9.1)$ & 0.923 \\
\hline Vomiting & & $3(3.0)$ & $2(6.3)$ & $0(0)$ & 0.429 \\
\hline \multirow[t]{2}{*}{ Increase of AST } & & $72(75.0)$ & $22(78.6)$ & $17(77.3)$ & 0.917 \\
\hline & $\begin{array}{l}\text { Increase in UI/I } \\
\text { (Median, SD) }\end{array}$ & $\begin{array}{l}48.0 \\
(742.8)\end{array}$ & $\begin{array}{l}39.0 \\
(122.3)\end{array}$ & $\begin{array}{l}66.0 \\
(198.9)\end{array}$ & 0.824 \\
\hline Increase of AST $>5 \times$ ULN & & $22(21.6)$ & $4(13.3)$ & $4(18.2)$ & 0.598 \\
\hline \multirow[t]{2}{*}{ Increase of ALT } & & $65(67.7)$ & $21(75.0)$ & $18(81.8)$ & 0.372 \\
\hline & $\begin{array}{l}\text { Increase in UI/I } \\
\text { (Median, SD) }\end{array}$ & $\begin{array}{l}26.0 \\
(526.8)\end{array}$ & $\begin{array}{l}22.0 \\
(41.4)\end{array}$ & $21.0(87.8)$ & 0.945 \\
\hline Increase of ALT >5 $x$ ULN & & $9(8.8)$ & $1(3.4)$ & $3(13.6)$ & 0.425 \\
\hline Portal vein fistula & & $1(1.0)$ & $3(9.4)$ & $0(0)$ & 0.027 \\
\hline GI-Ulcer & & $3(3.0)$ & $0(0)$ & $0(0)$ & 0.451 \\
\hline Cholecystitis & & $4(4.0)$ & $0(0)$ & $0(0)$ & 0.340 \\
\hline \multirow[t]{3}{*}{ Increase of Creatinine } & & $61(62.9)$ & $15(53.6)$ & $17(77.3)$ & 0.224 \\
\hline & $\begin{array}{l}\text { Increase in } \\
\mathrm{mg} / \mathrm{dl}\end{array}$ & $\begin{array}{l}0.07 \\
(0.25)\end{array}$ & $\begin{array}{l}0.06 \\
(0.07)\end{array}$ & $0.13(0.26)$ & 0.005 \\
\hline & (Median, SD) & & & & \\
\hline \multirow[t]{4}{*}{ Antibiotic treatment $(\mathrm{AB})$} & Periinterv. & $6(5.9)$ & $3(9.4)$ & $2(9.1)$ & 0.861 \\
\hline & Postinterv. & $3(3.0)$ & $1(3.1)$ & $2(9.1)$ & \\
\hline & After CRP $\uparrow$ & $19(18.8)$ & $6(18.8)$ & $4(18.2)$ & \\
\hline & Without $A B$ & $73(72.3)$ & $22(68.8)$ & $14(63.6)$ & \\
\hline Analgesic therapy post TACE & & $75(73.5)$ & $26(81.3)$ & $19(86.4)$ & 0.349 \\
\hline Hospital stay, days (median, & & $4(2-22)$ & $4(2-8)$ & $4(2-16)$ & 0.688 \\
\hline
\end{tabular}


ULN = upper limit of normal; UI = international unit; SD=standard deviation

\section{Figures}

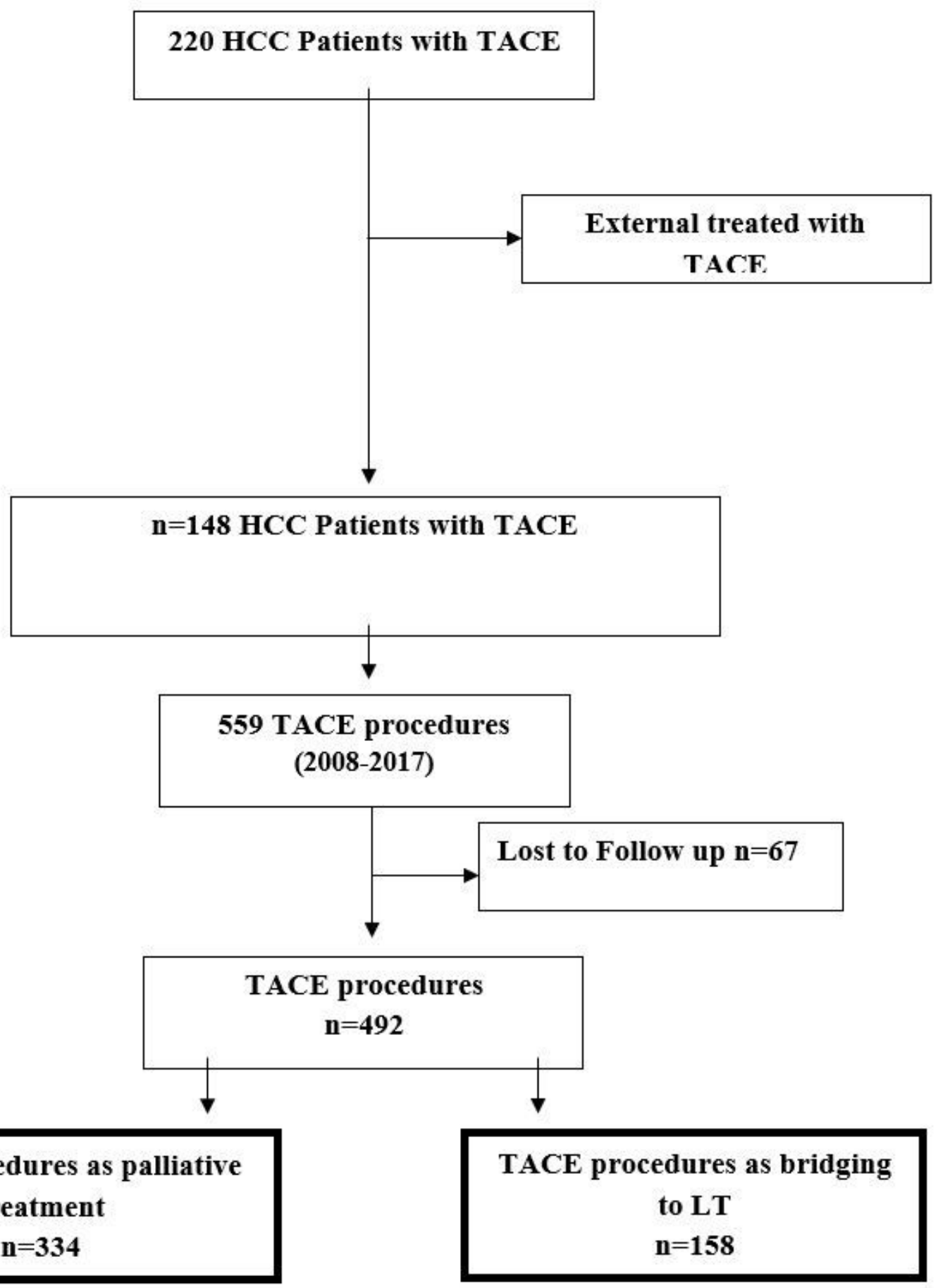

Figure 1 
Flow chart showing the selection of transarterial chemoembolization (TACE) procedures as well as the final number of included TACE procedures of different subgroups. 